\title{
Shared services centers and work sustainability: which contributions from ergonomics?
}

\author{
Justine Arnoud*, Pierre Falzon ${ }^{* *}$, \\ Ergonomics Laboratory, Research Center on Work and Development, Conservatoire National des Arts et Métiers \\ (CNAM), 41 rue Gay Lussac 75005 Paris France
}

\begin{abstract}
This study examines the way in which Shared Services Centers (SSCs) were implemented in a French multinational company. It aims to characterize the change according to the capabilities model developed by Amartya Sen: what are the effects of SSCs in terms of capabilities development and developmental quality of work, i.e. in the enabling potential of work? A 3-step methodology has been used: first, an investigation was conducted in a pay service of a local entity moving into SSC in 2013; second, two investigations were conducted in another pay service of a SSC: first, a few months after the change, and then, one year after the change (the same operators were interviewed). Results show a tendency to the decrease of the enabling potential. Additionally, it was noted that administrators are kept away from the design process and have to struggle with inappropriate rules. The efficiency and sustainability of the SSC are questioned; in this context, the human factor specialist has an important role to play.
\end{abstract}

Keywords: Strategic restructuring, organizational change assessment, enabling environment, ergonomic intervention, design process for sustainability

\section{Introduction}

Organizational changes have become a more or less permanent process in companies [8]. Often justified by a need for accommodating to an unstable environment, company managers trigger and lead changes in order to make the organization go from a state $\mathrm{A}$ to a state $\mathrm{B}[1]$.

Moving to Shared Services Centers (SSCs) represents a technical and organizational change often observed nowadays. This concept originated in the United States in the 1980s and appeared in Europe in the 1990s. A SSC is a separate and accountable semi-autonomous unit within an (inter)organizational entity, used to bundle activities and provide specific pre-defined services to the operational units within that (inter)organizational entity, on the basis of agreed conditions between provider and supplier [7].

The literature in management sciences advocates the economic and financial profits which can be expected by implementing SSCs: improvement of the quality of the service, economy of scale caused by mutualization, standardization of processes, possibility for the operational units to concentrate on their core business [2]. The change thus looks attractive. Leaders think that it is a source of enhanced performance although this added value is far from being systematic.

This movement falls within the framework of the emergence of the new forms of management where the outlines of the organization are redefined by what some authors call "strategic restructurings" [9]. These restructurings yield new ways of designing or organizing jobs and tasks. If they allow companies to

\footnotetext{
PhD Student, justine.arnoud@yahoo.fr

*** Professor, Chair of Ergonomics and neurosciences of work, pierre.falzon@cnam.fr
} 
adapt themselves better to the pressures of their environment, they also favour the emergence of new forms of vulnerability and precariousness still little considered [9].

The question of "sustainability" of work systems comes up: how can one create and maintain economically viable work systems that also contribute to human and social sustainability in a positive manner? In a sustainable work system, employees' capacity grows through work-based learning, development and well-being [3]. The capacities of employees thus suppose a favorable environment to be exercised. For that purpose, the working environment has to propose resources which allow capacities to become capabilities, i.e. a set of human functionings available to an individual, whatever their actual use [11].

The concept of enabling environment can constitute the central element of a model of liberty and development in work systems [5]. An enabling environment is an environment that makes it possible for people to develop new skills and knowledge, to enlarge their possibilities of action, their degree of control on their task and on the way in which they perform their task. For Sen, freedom is also a value of the human development, associated with personal fulfillment and self-recognition. In this perspective, the capabilities of the individuals would then correspond to the degree of autonomy of the operators, to their effective latitude. Similarly to the concept of sustainable freedom developed by Sen [13], a sustainable organization would preserve, and if possible, extend the liberties and the "capabilities" of all relevant stakeholders with a mid- or a long-term perspective : employees, shareholders, customers, suppliers, communities [15].

The results reported below stem from a study concerning an organizational change: the passage of a situation A still observable (the pay services in head offices and exploitations of the Group) in a situation B (the mutualization of these services within a Shared Services Center, a society of this Group recently created). The capability approach is mobilized as an analytic tool: it allows the investigator to assess the enabling potential of each of these environments and to see whether the change preserves, develops or hinders the capabilities of the pay agents, i.e. their autonomy and their freedom of choice.

\section{Method}

The company has set up, since 2008, four SSCs distributed over the French territory to supply, in each of the subsidiaries of its four divisions, administrative assistance, to the establishment of its accounting and its payslip services. The study focus its attention on the pay service in the SCC located in the Ilede-France (Paris and the surrounding departments), opened in April, 2010, and in the pay service of an entity which is planned to move towards an SSC in January 2013.

The methodology presented below seeks to investigate the notion of choice from the "functionings" observed to reach a partial but significant vision of the liberties [12] which individuals enjoy in situations A then B. Beyond the accomplished functionings, the effective possibilities and choice the pay administrators (i.e. their capabilities) are assessed.

The following methodology was used:

- individual interviews were carried out with different stakeholders: managers in both structures, correspondents in customer entities related to SSCs, professionals in charge of union management relations, heads of human resources. 26 interviews were carried out, recorded and transcribed;

- 3 administrators in the SSC and 3 in the local entity were interviewed; the interviews were semi-directed and included the following questions: what is your general appreciation regarding your work? Do you feel autonomous in your job? What are your objectives and do you manage to reach them? Does your work allow you to learn? For you, what is a work « well done »?

- observations of work were carried out with pay administrators. They have been used as information tools about the alternatives administrators really dispose of. Observations were conducted with:

- the same 3 operators in structure A (22 hours),

- the same 3 operators in structure B (21 hours) but one year after the interviews. It aims at understanding the evolution of the work organization into the SSC more than one year after their arrival. 


\section{Results}

Possessing adequate resources (such as knowing how to do something) is not sufficient for ensuring efficient mobilization. A favorable working environment is also needed, in order to transform a capacity into a capability. Such a favorable environment (sometimes referred to as "factors of favorable conversions") may even allow for the development of new resources, individual or collective.

\subsection{Before SSC: factors of capabilities development identified}

The first study was conducted within a wages department of a division; this service manages approximately 5300 pays distributed between 12 administrators (approximately 440 pays per administrator). It is situated in the office of the division. Thus, while the employees of the head office can interact face-to-face with their administrator, employees of other entities go through correspondents (one per entity) or contact directly the wages department by telephone or by email.

\subsubsection{Autonomous and high degree of control on tasks}

The administrators feel satisfied to manage pay files from A to Z. Pay files can concern one or several establishments. Besides pay processing, other aspects were observed: a "social" role that the administrators appreciate strongly, but also a role of advice and awareness actions for the local entity.

This complete management of the files comes along with a large autonomy on the whole process; while the work is realized under strong temporal constraint (payslip to be issued at the end of each month), administrators have the possibility to get organized as they wish, and to collect, as they think best, the information from various interlocutors. We observed requests for information addressed at colleagues, hierarchy, the HR service, the local entity, employees that the administrators call sometimes directly "to avoid intermediaries" etc.

This freedom in the way of organizing one's work is strengthened by a low evaluation pressure on the operators; indeed, there are no very precise criteria of evaluation and each administrator is supposed to produce accurate payslips, as long as the local entity passes information in time. The satisfaction of the employees (respect for deadlines and transparency) participates in the feeling of a well done work.
This possibility of realizing different tasks, the fact that work is designed so as to include a whole process rather than a process split up in multiple separate activities, are strongly appreciated by the administrators and can be considered as an important factor of development of capabilities at work.

\subsubsection{A "protected" service relationship and source of capabilities development for various stakeholders}

The administrators are grouped together in the HR service of a division; this service had been recently centralized. The fact is that a real service activity takes place but also and more importantly a service relationship occurs: there is a coproduction associated with a direct link between the person receiving benefits and the beneficiar. This relation goes through the telephone, the e-mail and face-to-face for one administrator who has direct local contact with the population he/she is in charge of. This relation strongly affects the present exercise conditions of the service: local information delivered in time or late, explanation of the changes of internal agreements, exchanges of information not formalized (susceptible to strengthen the commitments) etc.

The quality of this relation is thus essential; it appears besides in the criteria of evaluation of the administrators. During the annual interview, the hierarchy attributes a particular importance to "relations with the local entity". This criterion is very important:

- not only for the functioning and the performance of the service because the local entity participates in the activity of the administrators, in particular for checking payslips;

- but also for the development of the capabilities of the administrators; correspondents and administrators may find compromises in order to facilitate task completion. For instance, the local correspondent can send information earlier so that the administrator can take holiday during the pay period. Arrangements take place and allow the administrators to have a larger freedom.

\subsection{Work design in the SSC: the enabling potential hindered}

A comparative study was led within the Shared Services Centers of the Group where the first pay services began to be transferred in Spring 2008.

At the moment of the study (Autumn and Winter 2010), the pay service consisted of a person in charge of the service, two team leaders, nine pay administra- 
tors (approximately 310 pays per person), three persons in charge of the administrative part of the pay. During the setting up of the SSC project, the Group had decided to separate the administrative management (staff data and reports) from the pay management (the pay production strictly speaking) with the following idea: "the more you make repetitive tasks, the more successful you are" (Responsible for the pay service, SSC). A better productivity in terms of number of pays per person was expected.

\subsubsection{The principles of the new organization: which possibility for capabilities development in this context?}

- Service "at distance": a decrease of the available options

The pay production is remotely made so as to take away the operators of the constraints of the local "it is necessary to know that when you are close to your director or to your exploitation, you do not make necessarily only the pay (...) Here they produce only the pay " (Responsible for the pay service, SSC). Operators are requested to favour the communications by e-mail with the local entity, so as to leave traces and avoid wasting time with phone calls. No employee can call directly the SSC; each employee has to pass by a local HR correspondent who is the main interlocutor of the administrator.

As a consequence, the operator has fewer opportunities of exchanges with the local to look for information; the volume of available options decreases. This is detrimental since, as was noted previously, the exchange with the local entity is in itself a source of capabilities development.

Furthermore, the direct contact with the employee can, on the contrary, allow the operator to spare time. The organization of the work hinders not only the possibilities of choice but also the objectives of performance pursued.

- A Tayloristic approach of services: the possibilities of choice hindered

Due to the separation of the tasks between administrative and pay producer, operators no longer make everything from $\mathrm{A}$ to $\mathrm{Z}$ but only a part of the global task. Each one is forced to wait for the work of the other one. This wait is a source of tension within the service and hinders the possibilities for each one to choose their way of getting organized and of working.

We can wonder about the progressive transformation of the task engendered by the SSC organization: from the treatment of an employee towards the treatment of a file. The "history of the employee" becomes invisible with the separation of the tasks. The feeling to be more in an administrative, impersonal context than in a social activity increases.

The new distribution of tasks was supposed to increase productivity. However, it is not what performance measures show: the number of pay per person is superior in the division : 410 pays per person with portfolios going from 284 to 556 pays against 311 pays of average in the SSC with portfolios going from 204 to 482 pays.

The criteria of performance within the SSC do not seem to reflect the activity of the administrators. The industrialization seems difficult to set up.

\subsubsection{A model of regressive service: a service job without a service relationship relationship \\ - The establishment of a customer-supplier}

The study of the contract service and the interactions with the local revealed the existence of a customer-supplier relationship containing the following characteristics [10]:

- the SSC is supposed to know the expectations and the requirements of the customer (local entities);

- the local entity is supposed to know what it needs, otherwise, it will have to face the consequences: the payment of penalties. The director of the social relationships of a division said that his division "has to pay all the time"; we can then wonder about the legitimacy of this characteristic in the particular situation of the SSC;

- the skills and the knowledge are supposed sufficient on both sides. But the change towards SSC led to numerous difficulties for the local entity. A study is in progress to better characterize these phenomena;

- there are no objectives of learning: the unknown factors are considered as disruptive factors to surmount fast in order to ensure the progress of the contract.

- A service job without a service relationship: the possibilities of learning strongly reduced

As a matter of fact, the service within the SSC is thought without a service relationship; the industrialization of the pay production is looked for because it is thought to be synonymous with an increase in productivity. 
This vision of the job and of performance is based on a model of production of the payslip as planned beforehand, for customers whose requirements and expectations are known and stable. This hides the fact that the customers and their requests vary in a large way.

\subsection{Redesigning in practice but at what cost?}

\subsubsection{A separation of the tasks quickly revealed inefficient... Towards an increase of the autonomy?}

By going through the file of the procedures distributed to every administrator but little consulted in practice, a team leader underlined: "this is the procedures realized by the designers, the team project of the SSC. But there were quite a lot of changes and fast evolutions; when we saw that the procedures didn't work, we changed them". Redesigning in practice took place; among them, the division of the tasks initially planned between administrative and pay producer quickly proved to be ineffective and "a source of stress between the administrators because some people had to wait for the work of the others" (Team leader, SSC). Now, pay producers have taken back the control of files from $\mathrm{A}$ to $\mathrm{Z}$ even if the feeling to make less than before is always felt by the pay administrators one year later with a more important "mass of work" and "heavier" procedures (Administrators, SSC).

In reality, it is the freedom of choice which was previously limited and especially the obligation to wait for the work of the other one which bothered considerably pay producers. Today, administrative persons remain a "support" for pay producers sometimes confronted with a high workload and who can find help of administrative managers. This option is offered to them. Nevertheless, the "target organization" still plans the extinction of administrative managers.

\subsubsection{A work design still far from realities: which effects?}

The administrators have quickly asked for the distribution of the tasks to be reconsidered.

The strongly prescribed rules are put to the test of work reality. Job rules developed by the administrators during previous experiences in the Group are questioned within the SSC structure. A strong work of "hot regulation" is made by the operators.

Many examples illustrate the difficulty of putting designed rules into practice. Everyday, administrators have to tackle these rules, without understanding their utility, sometimes by working in a borderline way. Some rules have been eliminated but others are kept and require administrators to adapt. These daily regulations are felt as a source of stress and result in a "feeling to make bad work". Operators have the impression that the hierarchy does not understand their work: "We have been told that in the SSC, the organization would allow us to make quality payslip (...) For the moment, we do not have time to make that...just quantity. I make a worse and worse job, worse and worse pays..." (Pay producer, SSC)

\section{Discussion}

More and more, the attempt to shape the relationship with the customer into a technical and procedural rationality increases within the SSC: the actions of service, made by the worker, and the requests, made by the customer are defined beforehand in a framework which does not consider the difficulties and the unknown factors of the service production [14]. It is exactly the case in the SSC where the service contract that defines the SSC tries to turn variable situations into rigid ones, a clearly unrealistic and unproductive endeavour. Consequently, in their daily life at work, the administrators try to protect a good relationship with the customer entities and have to oppose to new rules.

As a matter of fact, we have been able to observe that the operators "fought" against rules and badly designed procedures. This "fight" allowed the administrators "to work", "to act", and sometimes "to be heard" (deletion of certain rules, new distribution of the tasks e.g.). But if on one side the organization may take into account their remarks when designed rules prove to be ineffective, on the other one the organization attempts more and more to enforce the procedures. So, some administrators apply some rules that they consider inappropriate or as a waste of time. They force themselves not to act in the way they would have wished to.

The human factors specialist can help the organization by shedding a light on the real demands of the task, on the inconsistencies of the prescribed work design in terms of quality production, on the tradeoffs of the operators in the SSC and by measuring the impact of these trade-offs on health.

Moreover, ergonomic studies have emphasized the benefits of user participation in system design: participatory ergonomics may be a particular macroergonomic tool that can help realize global sustain- 
able development [6]. SSC is still in the process of design; it would thus be relevant to consider this participation and the modalities of this participation to favour:

- the development of capabilities during the design process itself,

- but also the offer of an "enabling environment" once stabilized, i.e. an environment allowing one to develop their skills, thus defining a sustainable work context [4].

It turns out that the organization should include end users not only in the design process for work but also for sustainability.

\section{References}

[1] P. Bernoux, Sociologie du changement dans les entreprises et les organisations, Seuil, Paris, 2004

[2] F. L. Cook, Modeling an HR Shared Services Center: experience of an MNC in the United Kingdom, Human Resource Management, Vol. 45, No. 2, Summer 2006, pp. 211-227.

[3] P. Docherty, M. Kira \& A.B. Shani, Creating sustainable work systems, Routledge, ed., London \& New-York, 2009.

[4] P. Falzon, Ergonomics, knowledge development and the design of enabling environments. Proceedings of the Humanizing Work and Work Environment HWWE'2005 Conference, December 10-12 Guwahati, India, 2005, 1-8.
[5] P. Falzon, Enabling safety: issues in design and continuous design. Cognition Technology and Work, 10 (1), 7-14 (published on line: April 4, 2007).

[6] A.S. Imada, Achieving Sustainability through Macroergonomic Change Management and Participation. In K.J. Zink (Ed.) Corporate sustainability as a Challenge for Comprehensive Management, Physica-Verlag, Heidelberg, 2008, pp. 129-138.

[7] M. Janssen \& A. Joha, Motives for establishing shared services centers in public administrations, International Journal of Information Management 26, 2006, pp. 102-115.

[8] J. Petit, Organiser la continuité du service : Intervention sur l'organisation d'une Mutuelle de santé, Ergonomics Ph.D. Dissertation, Bordeaux 2, 2005.

[9] B. Rorive, Restructurations stratégiques et vulnérabilité au travail. Revue de l'IRES, 47(1), Paris, 2005, pp. 117-134.

[10]J.-C. Sardas, Relation de partenariat et recomposition des métiers, in : F. Hubault (coord.) La relation de service, opportunités et questions nouvelles pour l'ergonomie. Toulouse : Octarès, 2002.

[11]A. Sen, Development as freedom. Oxford: Oxford University Press, 1999.

[12]A. Sen, Inequality Reexamined, Harvard University Press, 1992.

[13]A. Sen, The Idea of Justice, Penguin Books, Ltd, London, 2009.

[14]L.I. Sznelwar, F.L. Mascia \& G. Bouyer, L'empêchement au travail : une source majeure de TMS ? @ ctivités, vol. 3, n² 2006.

[15]K.J. Zink, U. Steimle \& K. Fischer, Human Factors, Business Excellence and Corporate Sustainability: Differing Perspectives, Joint Objectives. In K.J. Zink (Ed.) Corporate sustainability as a Challenge for Comprehensive Management, Physica-Verlag, Heidelberg, 2008, pp.3-17. 